Wie aus Wildnis Gesellschaft wird 
Jörn Ahrens

\section{Wie aus Wildnis \\ Gesellschaft wird}

Kulturelle Selbstverständigung

und populäre Kultur am Beispiel

von John Fords Film

"The Man Who Shot Liberty Valance“

Springer VS 
Jörn Ahrens

Universität Gießen, Deutschland

ISBN 978-3-531-16774-9

ISBN 978-3-531-93238-5 (eBook)

DOI 10.1007/978-3-531-93238-5

Die Deutsche Nationalbibliothek verzeichnet diese Publikation in der Deutschen Nationalbibliografie; detaillierte bibliografische Daten sind im Internet über http://dnb.d-nb.de abrufbar.

\section{Springer VS}

(C) VS Verlag für Sozialwissenschaften | Springer Fachmedien Wiesbaden 2012

Das Werk einschließlich aller seiner Teile ist urheberrechtlich geschützt. Jede Verwertung, die nicht ausdrücklich vom Urheberrechtsgesetz zugelassen ist, bedarf der vorherigen Zustimmung des Verlags. Das gilt insbesondere für Vervielfältigungen, Bearbeitungen, Übersetzungen, Mikroverfilmungen und die Einspeicherung und Verarbeitung in elektronischen Systemen.

Die Wiedergabe von Gebrauchsnamen, Handelsnamen, Warenbezeichnungen usw. in diesem Werk berechtigt auch ohne besondere Kennzeichnung nicht zu der Annahme, dass solche Namen im Sinne der Warenzeichen- und Markenschutz-Gesetzgebung als frei zu betrachten wären und daher von jedermann benutzt werden dürften.

Satz: text plus form, Dresden

Einbandentwurf: KünkelLopka GmbH, Heidelberg

Gedruckt auf säurefreiem und chlorfrei gebleichtem Papier

Springer VS ist eine Marke von Springer DE. Springer DE ist Teil der Fachverlagsgruppe Springer Science+Business Media

www.springer-vs.de 


\section{Inhalt}

1 Einleitung: Kultur, Gesellschaft und John Fords The Man Who Shot Liberty Valance

2 Der Western als Gründungserzählung $\quad \ldots \ldots \ldots \ldots \ldots \ldots \ldots \ldots \ldots \ldots \ldots \ldots \ldots \ldots \ldots$

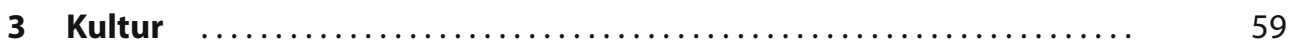

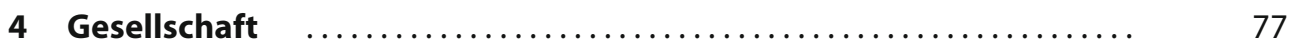

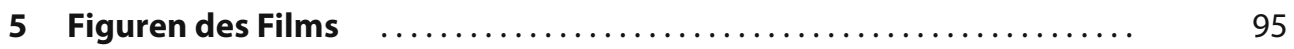

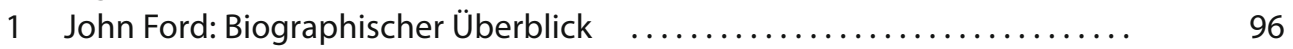

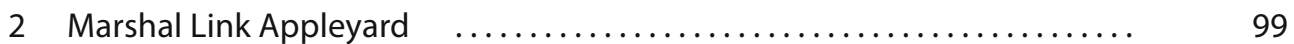

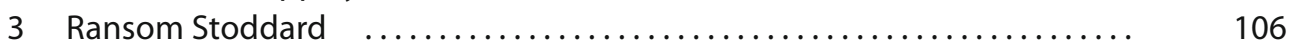

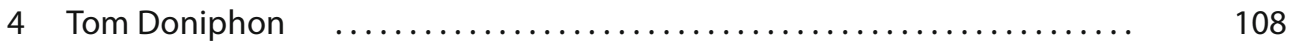

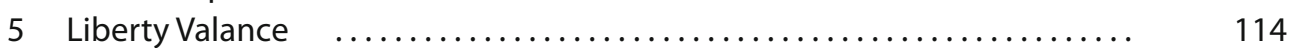

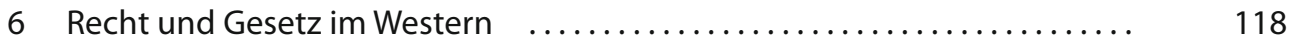

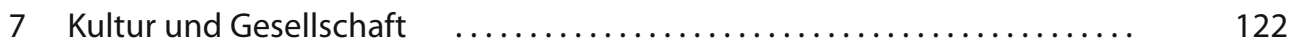

6 Subjektivität und Anomie oder Die Unmöglichkeit von Freiheit und Vergesellschaftung $\quad \ldots \ldots \ldots \ldots \ldots \ldots \ldots \ldots \ldots \ldots \ldots$



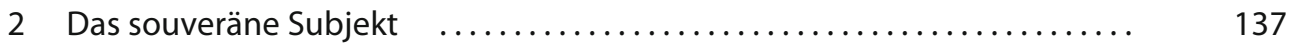

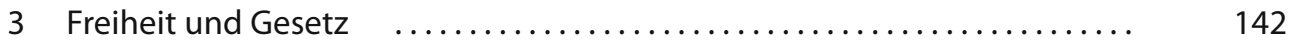

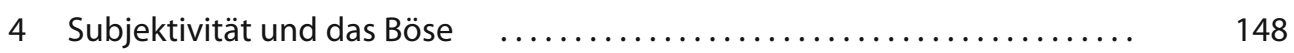

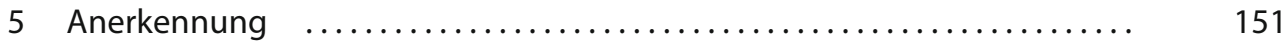

7 Das Böse in der Gesellschaft und die Erziehung

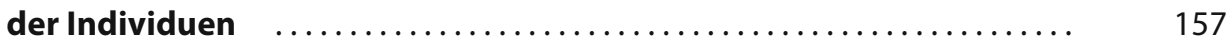

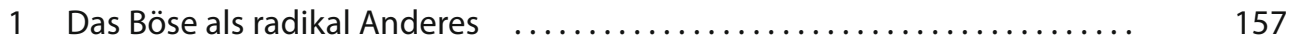

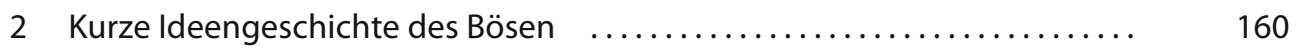

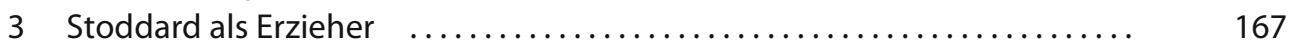




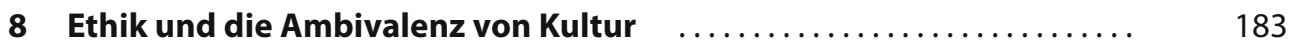

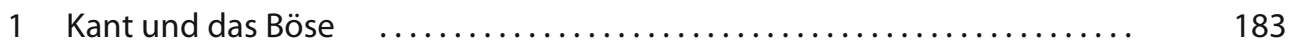

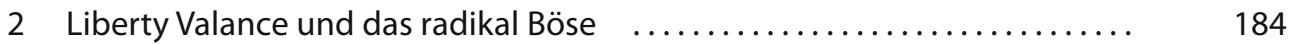

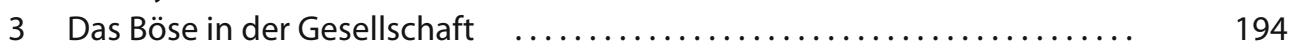

4 Vergebliche Liebesmüh: Zum Versuch,

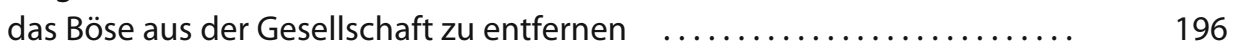

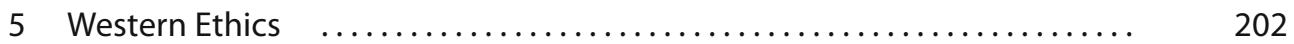

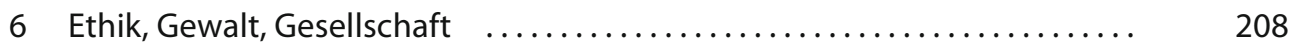

9 Gesellschaft als Verrechtlichung der Wildnis $\ldots \ldots \ldots \ldots \ldots \ldots \ldots$

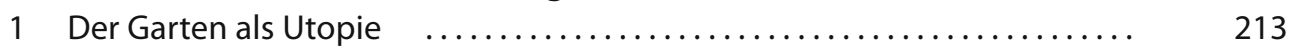

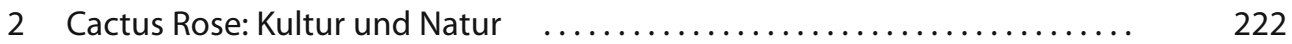

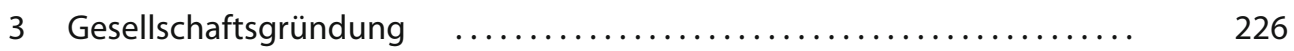

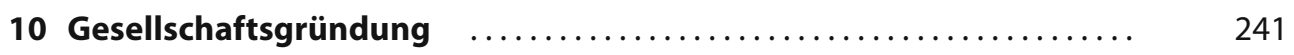

11 Kultur und die Bereitstellung von Imaginationsräumen $\ldots \ldots \ldots \ldots .267$

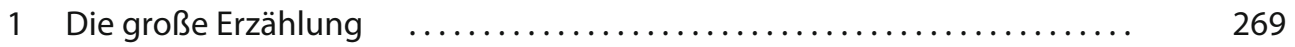

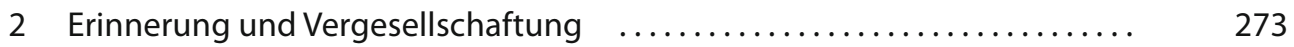

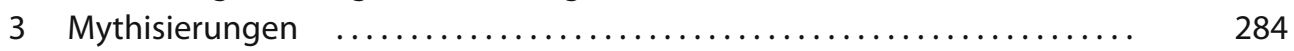

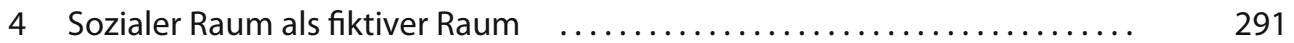

12 Praktiken kultureller Selbstvergewisserung $\ldots \ldots \ldots \ldots \ldots \ldots \ldots \ldots \ldots$

1 Filmische Selbstvergewisserung als Kulturtechnik $\ldots \ldots \ldots \ldots \ldots \ldots \ldots . \ldots 29$

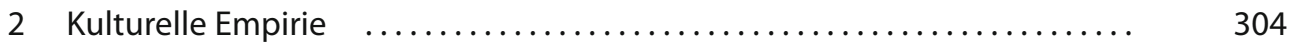

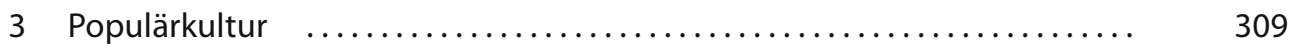

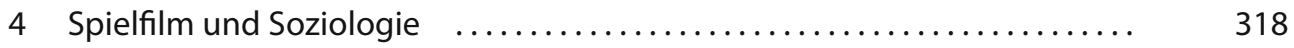

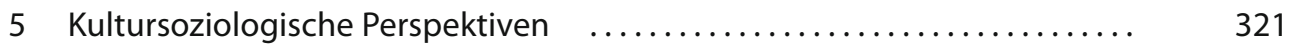

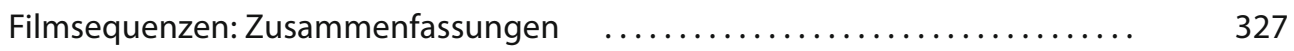

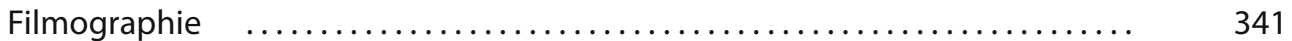

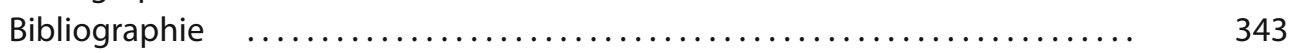

